\title{
Uniformly dispersed deposition of colloidal nanoparticles and nanowires by boiling
}

\author{
Kyumin Lee, ${ }^{\text {a) }}$ M. Duchamp, G. Kulik, A. Magrez, Jin Won Seo, ${ }^{\text {b) }}$ S. Jeney, \\ A. J. Kulik, and L. Forró \\ Ecole Polytechnique Fédérale de Lausanne (EPFL), Institute of Physics of Complex Matter, CH-1015 \\ Lausanne, Switzerland \\ R. S. Sundaram and J. Brugger \\ Ecole Polytechnique Fédérale de Lausanne (EPFL), Institute of Microelectronics and Microsystems, \\ CH-1015 Lausanne, Switzerland
}

(Received 20 July 2007; accepted 8 October 2007; published online 23 October 2007)

\begin{abstract}
Uniformly dispersed deposition of various nanoparticles (gold and silver of 20-50 nm) and nanowires $\left(\mathrm{ZnO}\right.$ and $\mathrm{VO}_{x}$ ) on different surfaces ( $\mathrm{Si}, \mathrm{GaAs}$, mica, and steel) was obtained by boiling colloid drops on preheated substrates. Our results suggest a deposition mechanism based on the formation of microdrops induced by boiling. Indeed, microdrops produced by an ink-jet printing system resulted in uniformly dispersed deposits when the substrate was heated to high temperatures. We demonstrate that boil-deposited gold nanoparticles could be used for the catalytic growth of $\mathrm{ZnO}$ nanowires as well as for the manipulation of individual particles by means of an atomic force microscope. (C) 2007 American Institute of Physics. [DOI: 10.1063/1.2803320]
\end{abstract}

Properties of nanoparticles (NPs) and nanowires (NWs) are of great interest to the scientific community. ${ }^{1,2}$ Various NPs of well-defined size, composition, and shape are available as colloids, ${ }^{3,4}$ and breakthroughs in the solution-phase synthesis of NWs have also made these nanostructures available in the colloidal form. ${ }^{2}$ To study the properties of single NPs or NWs, the objects need to be placed on solid substrates, spaced farther apart than the spatial resolution of the probing method. Uniform deposition is preferable for scanning probe microscopy methods that have limited image acquisition rates.

However, uniformly well-separated (or dispersed) deposition usually cannot be achieved by simply drying a colloid drop on a substrate. Surface asperities and solute particles pin down the contact line, creating a radial outward flow when the solvent evaporates. ${ }^{5}$ The laminar flow drags solute particles outward and forms a ringlike deposit. When the solvent layer becomes thinner than the particles, capillary forces pull the deposited particles into a close-packed arrangement. $^{6}$ Methods such as self-assembly ${ }^{7}$ and spin coating $^{8}$ are available to overcome or circumvent these phenomena.

The radial flow and the strong capillary forces are properties of a drying drop. What if the drop boils on a hot surface? Laminar flow would not develop in a turbulently boiling drop, and the solvent may evaporate away before particles aggregate. Intuitively, boiling appears to be a possible route to the dispersed deposition of colloidal particles.

To test the feasibility of boil deposition, we boiled colloid drops of various NPs and NWs on different substrates. Gold (40 and $50 \mathrm{~nm}$ ) and silver $(20 \mathrm{~nm})$ colloids from British Biocell International were diluted 10-1000 times in deionized water or ethanol. Vanadium oxide $\left(\mathrm{VO}_{x}\right)$ nanotubes (NTs) were synthesized by a solution-phase process ${ }^{9}$ and di-

\footnotetext{
${ }^{\text {a)} E l e c t r o n i c ~ m a i l: ~ l e e . k y u m i n @ g m a i l . c o m ~}$

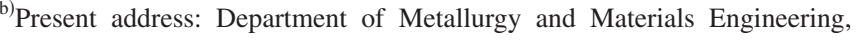
Katholieke Universiteit Leuven, Belgium.
}

luted in cyclohexane. Zinc oxide $(\mathrm{ZnO}) \mathrm{NWs}$ were grown by chemical vapor deposition ${ }^{10}$ (CVD) and suspended in ethanol by sonication. As substrates, pieces (typical size of $1 \times 1 \mathrm{~cm}^{2}$ ) of silicon ( $\mathrm{Si}$ ) wafer, gallium arsenide (GaAs) wafer, cleaved mica, and mirror-polished steel were used. All substrates except mica were first cleaned by ultrasonic bath in de-ionized water and ethanol and then by plasma cleaning in air.

After heating up a substrate on a hot plate, we placed a few $2-3 \mathrm{~mm}(4-15 \mu \mathrm{l})$ drops of colloid on the substrate and left them to boil. On poor thermal conductors such as GaAs wafer and mica, boiling often ceased midway due to the limited heat transfer rate and the local substrate cooling. Indirect boiling was carried out on these substrates; drops were boiled on an adjacent steel plate, and the deposition was achieved through microdrops $(20-100 \mu \mathrm{m}$ and 4-500 pl) ejected from the main boiling drop. The direct and the indirect methods are illustrated in Figs. 1(a) and 1(b). The optimum heater temperature varied with the substrate and the colloid solvent (Table I).

The surfaces were then studied by optical microscopy, atomic force microscopy (AFM), and scanning electron microscopy (SEM). Under an optical microscope, partial

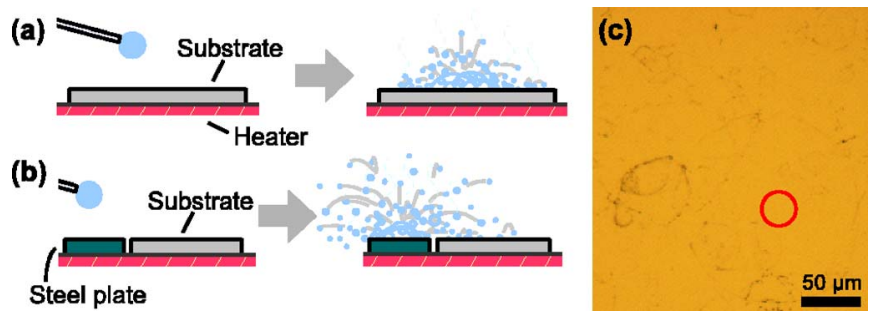

FIG. 1. (Color online) (a) Colloid drops were normally boiled directly on the substrate. (b) For a substrate of low thermal conductivity, colloid drops were boiled on an adjacent steel plate. (c) Optical microscopy showed complex patterns on a surface related to the microdrops created by boiling. Optically clean areas, such as the region inside the red circle, revealed dispersed deposits when studied with SEM and AFM. 
TABLE I. Heater temperatures for different substrates and colloids.

\begin{tabular}{cccc}
\hline \hline Substrates & Boiling method & $\begin{array}{c}\text { Colloid in water } \\
\left({ }^{\circ} \mathrm{C}\right)\end{array}$ & $\begin{array}{c}\text { Colloid in ethanol } \\
\left({ }^{\circ} \mathrm{C}\right)\end{array}$ \\
\hline Si wafer & Direct & $150-200$ & $100-160$ \\
GaAs wafer & Indirect & $140-190$ & $90-150$ \\
Mica & Indirect & & $150-250$ \\
Polished steel & Direct & $140-190$ & $90-150$ \\
\hline \hline
\end{tabular}

contact-line deposits from microdrops were visible [Fig. 1(c)]. Regions that looked "clean" showed dispersed deposition of NPs and NWs when studied with AFM and SEM. Images of dispersed gold NPs on three different substrates, silver NPs on cleaved mica, $\mathrm{VO}_{x}$ NTs on $\mathrm{Si}$, and $\mathrm{ZnO} \mathrm{NWs}$ on $\mathrm{Si}$ are shown in Fig. 2.

The deposition was generally uniform throughout a substrate, and its density depended on the concentration and the volume of colloid used. Occasionally, aggregates of two or several particles were present, but the majority were single particles. For particles larger than $20 \mathrm{~nm}$, single particles were easily distinguishable from aggregates with AFM and SEM.

While we could quickly find the optimum temperatures for deposition, the complexity of liquid-drop dynamics on a
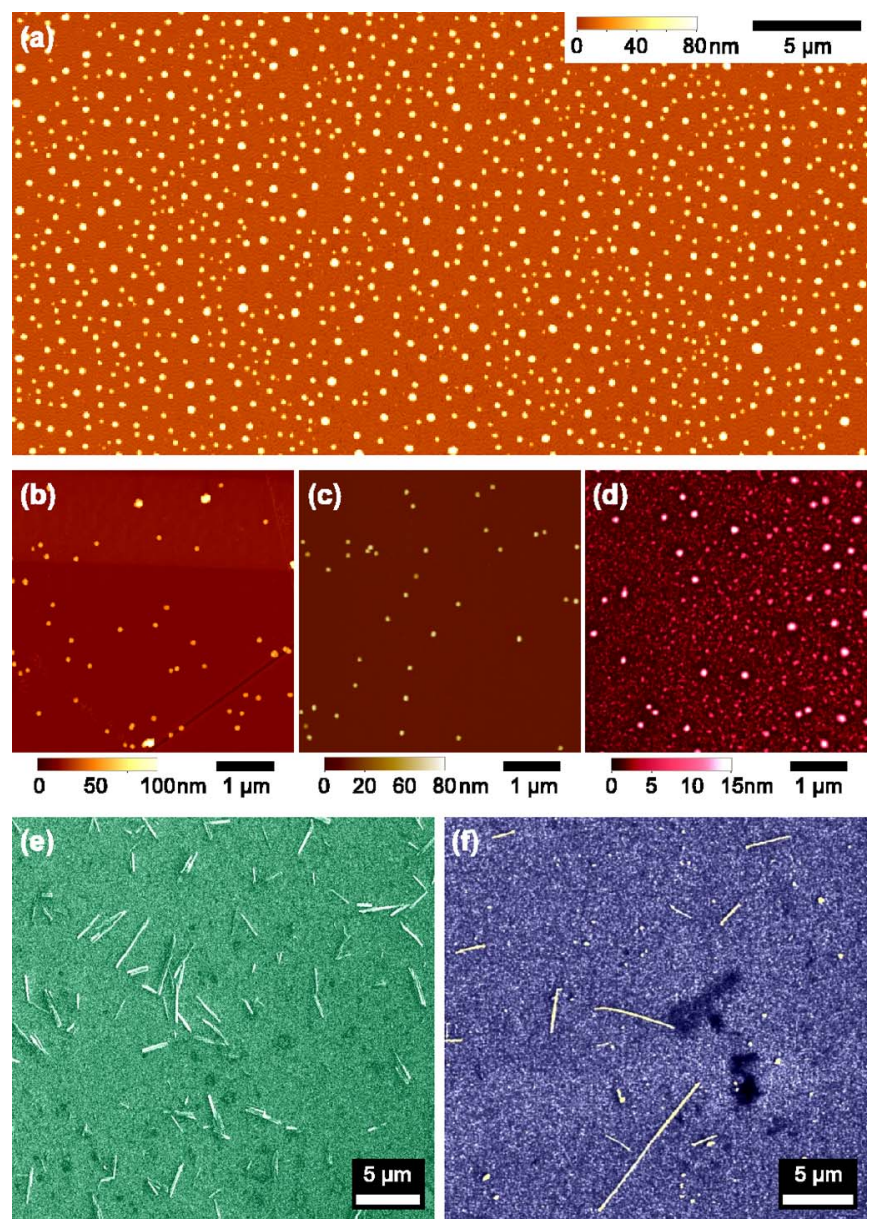

FIG. 2. (Color online) AFM images of (a) $40 \mathrm{~nm}$ gold NPs on $\mathrm{Si}$ (water as solvent; direct boiling; heater at $180^{\circ} \mathrm{C}$ ), (b) $50 \mathrm{~nm}$ gold NPs on polished steel (water; direct; $190^{\circ} \mathrm{C}$ ), (c) $50 \mathrm{~nm}$ gold NPs on GaAs (water; indirect; $170{ }^{\circ} \mathrm{C}$ ), and (d) $20 \mathrm{~nm}$ silver NPs on mica (ethanol; indirect; $160{ }^{\circ} \mathrm{C}$ ). SEM images of (e) $\mathrm{VO}_{x} \mathrm{NTs}$ on $\mathrm{Si}$ (cyclohexane; direct; $230{ }^{\circ} \mathrm{C}$ ) and (f)

ZnO NWs on Si (ethanol; direct; $140{ }^{\circ} \mathrm{C}$ ).
Downloaded 25 Oct 2007 to 128.178 .153 .168$. Redistribution subject to AlP license or copyright, see http://apl.aip.org/apl/copyright.jsp

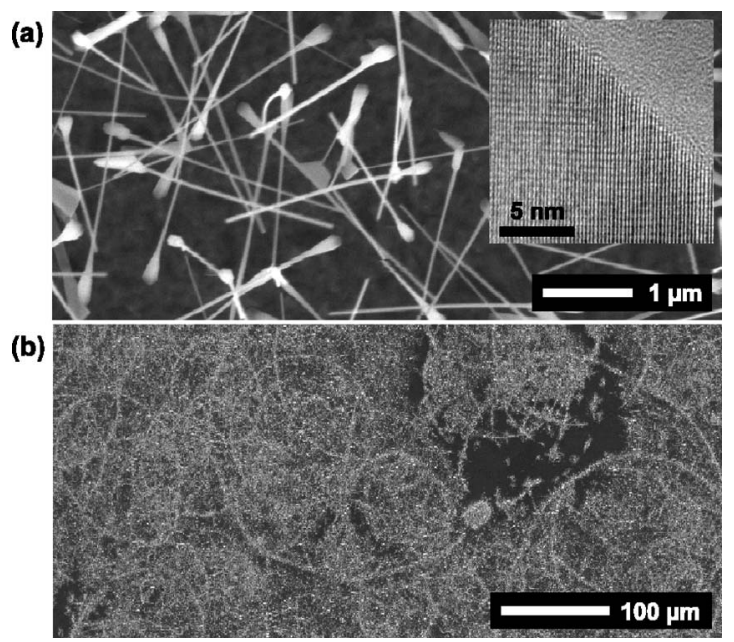

FIG. 3. ZnO NWs could be grown from $50 \mathrm{~nm}$ gold NPs boil deposited on a Si wafer. (a) A high-magnification SEM image shows NWs originating from individual NPs. As the representative TEM image (inset) shows, the NWs were single crystalline. (b) A low-magnification SEM image of ZnO NWs gives an enhanced view of the gold NP deposit patterns.

hot surface ${ }^{11,12}$ made it difficult to understand the deposition mechanism. However, SEM images of $\mathrm{ZnO}$ NWs grown by CVD from boil-deposited gold NPs offered a valuable insight. As can be seen in the high-magnification SEM image [Fig. 3(a)], single-crystalline nanowires originated from individual gold NPs. As-grown $\mathrm{ZnO} \mathrm{NWs}$ gave high-contrast SEM images even at low magnifications, as opposed to the gold NPs that were practically invisible at such scales. The low-magnification $\mathrm{ZnO} \mathrm{NW}$ images highlighted various patterns in the gold NP deposit and showed it to be a superposition of microdrop deposits [Fig. 3(b)]. Hence, we were led to consider if the actual deposition occurred through microdrops.

The microdrop deposition model was supported by additional observations. A nucleate-boiling drop that ejected and dissociated into microdrops was necessary for a uniform deposition. Deposition could not be achieved with rapidly drying or film-boiling (buoying on its own vapor) drops that did not eject microdrops. Upon monitoring the process with an optical microscope, we also learned that the microdrops must wet the surface. If a substrate was so hot that the microdrops slid off without wetting (Leidenfrost effect), dispersed deposition did not occur. As microdrops drying at room temperature were known to leave behind ringlike deposits such as larger drops, ${ }^{13}$ questions remained as to how they behave on hot surfaces.

Using an ink-jet printing system (Microdrop MD-K130), we deposited individual $20 \mathrm{pl}(30-40 \mu \mathrm{m})$ microdrops of $50 \mathrm{~nm}$ gold colloid on $\mathrm{Si}$ wafer at different temperatures $\left(110-170{ }^{\circ} \mathrm{C}\right)$. At these temperatures, a microdrop does not boil because the evaporation time is very short. ${ }^{11}$ Concentric ringlike deposits were left by single microdrops evaporating at low temperatures $\left(110-130{ }^{\circ} \mathrm{C}\right)$ [Fig. 4(a)], but uniformly dispersed deposits were obtained for higher temperatures $\left(150-170{ }^{\circ} \mathrm{C}\right)$ [Figs. 4(b) and 4(c)]. A competition between self-pinning and dewetting is known to cause the contact line to jump, ${ }^{14}$ and a microdrop in such a state would leave behind concentric deposits [Fig. 4(d)]. However, at sufficiently high temperatures, a microdrop seems to dewet smoothly possibly because of heating-related contact-line perturbations AIP license or copyright, see http://apl.aip.org/apl/copyright.jsp 


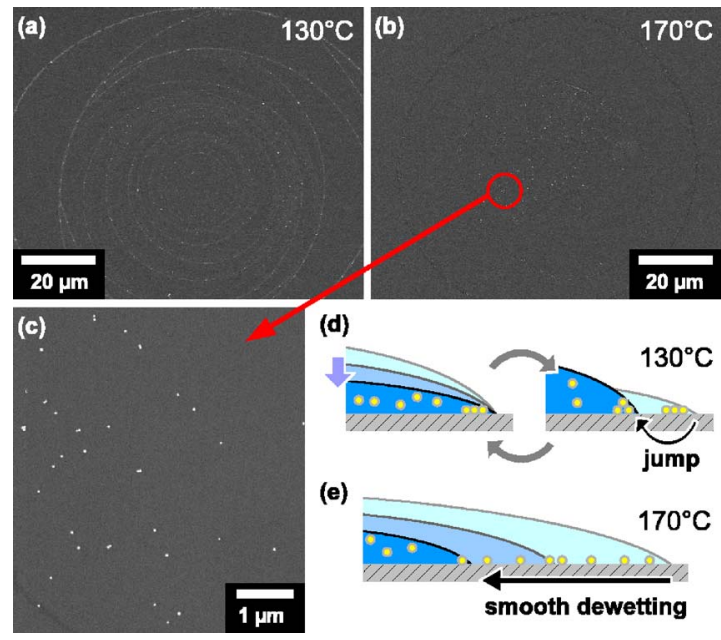

FIG. 4. (Color online) SEM images of (a) the deposit from a $20 \mathrm{pl}$ gold colloid microdrop on a $\mathrm{Si}$ wafer when heater was at $130{ }^{\circ} \mathrm{C}$ and (b) the deposit from a similar drop when the heater was at $170{ }^{\circ} \mathrm{C}$. (c) The $170{ }^{\circ} \mathrm{C}$ deposit showed a dispersed deposition. A microdrop may evaporate through either (d) a series of contact-line jumps or (e) smooth dewetting, depending on the substrate temperature.

that prevent self-pinning [Fig. 4(e)]. Hence, we propose a two-step mechanism for boil deposition: (1) a millimetersized drop ejects and finally dissociates into microdrops and (2) the microdrops dewet smoothly when evaporating, resulting in the dispersed deposition of solute particles.

We found boil deposition more convenient and efficient than conventional methods such as self-assembly and spin coating. In self-assembly, surface functionalization is a crucial step that requires a scrupulous cleaning and handling of substrates, and the procedures vary significantly for different materials. ${ }^{7}$ In boil deposition, bare substrates can be used, and basic cleaning procedures are often sufficient. The method can be applied to different substrates and colloids with little or no change in the details. While self-assembly typically takes a few hours to a few days, boil deposition can be carried out in a few minutes. Boil deposition thus allows a faster preparation with significantly less effort. Compared to spin coating, we found boil deposition to give better results with fewer aggregates, and the results were less sensitive to solvent viscosity.

In addition to NW growth, the surface-dispersed NPs could be used for nanomanipulation experiments; 40 and $50 \mathrm{~nm}$ gold NPs boil deposited on Si wafer were displaced by AFM using the method described by Ritter et al. ${ }^{15}$ As boil deposition is applicable to different NPs and substrates, nanometer-scale friction in various particle-substrate systems has been studied. These results will be published elsewhere.

To summarize, we found that boiling leads to the uniformly dispersed deposition of colloidal NPs and NWs. The method is simple and efficient, and it can be applied to a wide range of colloids and surfaces. The deposition seems to occur through microdrops (created during the boiling of millimeter-sized drops) that dewet smoothly at elevated temperatures and leave behind uniformly surface-dispersed solute particles. We will study the mechanism in greater detail by high-speed imaging of microdrop dynamics. ${ }^{12}$ We also plan to combine lithography with boil deposition by ink-jet printing.

The toxicity of NPs and NWs is still under investigation. Boil deposition should be carried out in a fume hood or a glove chamber with appropriate safety precautions.

We thank G. Beney for polishing the steel substrates, G. Camarda for various machining work, C. Dieker for highresolution transmission electron microscope (TEM) imaging, and the Centre Interdisciplinaire de Microscopie Electronique (CIME) at EPFL for access to electron microscopes and technical support. This work was funded by the National Center of Competence in Research "Nanoscale Science" of the Swiss National Science Foundation and the European (Project No. IST-ET4US-2048) "Epitaxial Technologies for Ultimate Scaling."

${ }^{1}$ M. Brust and C. J. Kiely, Colloids Surf., A 202, 175 (2002).

${ }^{2}$ Y. Xia, P. Yang, Y. Sun, Y. Wu, B. Mayers, B. Gates, Y. Yin, F. Kim, and H. Yan, Adv. Mater. (Weinheim, Ger.) 15, 353 (2003).

${ }^{3}$ Y. Sun and Y. Xia, Science 298, 2176 (2002).

${ }^{4}$ Y. Yin and A. P. Alivisatos, Nature (London) 437, 664 (2005).

${ }^{5}$ R. D. Deegan, O. Bakajin, T. F. Dupont, G. Huber, S. R. Nagel, and T. A. Witten, Nature (London) 389, 827 (1997).

${ }^{6}$ N. D. Denkov, O. D. Velev, P. A. Kralchevsky, I. B. Ivanov, H. Yoshimura, and K. Nagayama, Langmuir 8, 3183 (1992).

${ }^{7}$ A. N. Shipway, E. Katz, and I. Willner, ChemPhysChem 1, 18 (2000).

${ }^{8}$ Y.-K. Hong, H. Kim, G. Lee, W. Kim, J.-I. Park, J. Cheon, and J.-Y. Koo, Appl. Phys. Lett. 80, 844 (2002).

${ }^{9}$ F. Krumeich, H.-J. Muhr, M. Niederberger, F. Bieri, B. Schnyder, and R. Nesper, J. Am. Chem. Soc. 121, 8324 (1999).

${ }^{10}$ M. H. Huang, Y. Wu, H. Feick, N. Tran, E. Weber, and P. Yang, Adv. Mater. (Weinheim, Ger.) 13, 113 (2001).

${ }^{11}$ P. Tartarini, G. Lorenzini, and M. R. Randi, Heat Mass Transfer 34, 437 (1999).

${ }^{12}$ H.-Y. Kim, S.-Y. Park, and K. Min, Rev. Sci. Instrum. 74, 4930 (2003).

${ }^{13}$ J. Park and J. Moon, Langmuir 22, 3506 (2006).

${ }^{14}$ R. D. Deegan, Phys. Rev. E 61, 475 (2000).

${ }^{15}$ C. Ritter, M. Heyde, U. D. Schwarz, and K. Rademann, Langmuir 18, 7798 (2002) 